\title{
Conventional and Non-conventional Sintering Techniques of High Purity Alumina Ceramics
}

\author{
Ivana ROPUŠ*, Lidija ĆURKOVIĆ, Vilko MANDIĆ, Mihone KEROLLI MUSTAFA, Ivana GABELICA
}

\begin{abstract}
The goal of this study is to compare the properties of cold isostatically pressed (CIP) alumina $\left(\mathrm{A}_{2} \mathrm{O}_{3}\right)$ samples sintered by conventional (electrical) and nonconventional (hybrid microwave) techniques. X-ray diffraction was used to determine phase composition of $\mathrm{A}_{2} \mathrm{O}_{3}$ samples (raw powder and granules). Thermogravimetric analysis (TGA) and differential thermal analysis (DTA) were used to investigate the thermal behaviour of the $\mathrm{Al}_{2} \mathrm{O}_{3}$ powder and granules during the thermal treatment. Compaction of spray dried $\mathrm{A}_{2} \mathrm{O}_{3}$ granules into green compact bodies was performed by $\mathrm{CIP}$, followed by sintering of green bodies at $1600{ }^{\circ} \mathrm{C}$ in an electrical and hybrid microwave kiln, respectively. Scanning electron microscopy (SEM) was used to analyse morphology of the $\mathrm{Al}_{2} \mathrm{O}_{3}$ granules and fracture surface of $\mathrm{Al}_{2} \mathrm{O}_{3}$ compacts derived by both sintering techniques. Higher linear shrinkage and densification were obtained for alumina samples sintered in electrical kiln (conventional method), while sintering by faster and more energy efficient hybrid microwave kiln (non-conventional sintering method) yielded alumina samples with finer grain size. Alumina samples sintered by electrical kiln displayed higher relative densities and lower porosities.
\end{abstract}

Keywords: alumina ceramics; conventional sintering; hybrid microwave sintering; shrinkage

\section{INTRODUCTION}

Aluminium oxide or alumina $\left(\mathrm{Al}_{2} \mathrm{O}_{3}\right)$ is an oxide technical ceramic material with $\alpha-\mathrm{Al}_{2} \mathrm{O}_{3}$, the most stable form thermodynamically. Also, alumina exists in several metastable polymorphs such as $\gamma, \delta, \eta, \theta, \kappa, \chi[1,2]$. Alumina shows properties such as high elastic modulus, high wear resistance, high chemical corrosion resistance, high temperature stability, retention of strength at high temperatures but also brittleness and low fracture toughness $[3,4]$.

Commonly, alumina is the first choice as refractory material because of the low cost, simple handling and production [5]. Biocompatibility makes alumina as high potential material in medicine application (dental, cardiologic, orthopaedic, bionic) [6, 7]. High purity alumina ( $>99.5$ wt. \%) may be used as structural element and electric insulator in nuclear reactors, for corrosion and wear protection, in automobile and spacecraft industry, in environmental industries, also in water vapour processing, as well as in oil and gas energy production [7, 8].

Final properties and microstructure of the ceramic material depend on each step of the production process: powder preparing, shaping of the green bodies and sintering process $[9,10]$.

Compacted green body can be sintered at elevated temperatures by conventional or non-conventional sintering methods. As opposed to conventional sintering, where heat is transferred via conduction from the outside to the inside of the material (Fig. 1a), in the microwave heating process the heat is generated internally within the material and transmitted outwards (Fig. 1b). Microwave heating is a function of the material being processed. Microwave heating can utilise almost all electromagnetic energy into heat, largely within the sample itself, unlike with conventional heating where the conversion is lower due to significant thermal energy losses. Microwave heating has many advantages like time and energy saving, very high heating rates $\left(>400{ }^{\circ} \mathrm{C} / \mathrm{min}\right)$, considerably reduced processing time and temperature, fine microstructures and with that improved mechanical properties [4, 11].

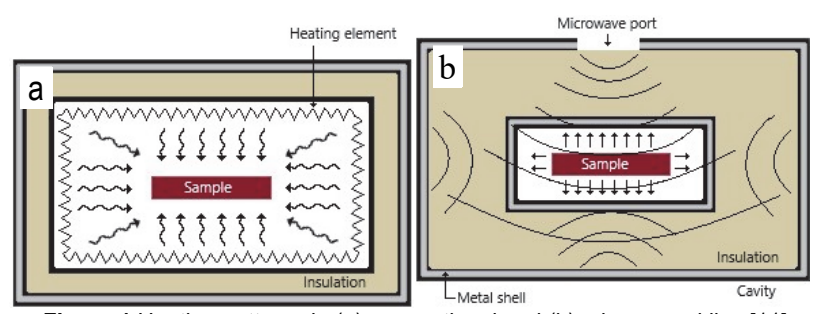

Figure 1 Heating patterns in (a) conventional and (b) microwave kilns [11]

Microwave hybrid heating techniques were developed to improve heat transfer to the sintering samples. It combines direct microwave heating with e.g. infrared heat sources. The hybrid heating systems enable flattening of the temperature profile inside the ceramic body during sintering [4]. The materials with low microwave radiation absorption (high reflectance) should be heated using e.g. susceptor as material absorbing microwave radiation in order not to damage magnetrons during process [4]. For this purpose, $\mathrm{SiC}$ may be used [12]. Microwave technology is very attractive because of economic benefits such as energy conservation, reduced sintering time, reduced operating space. Furthermore, microwave sintering drastically suppresses grain growth during densification [13]. Therefore, in past two decades microwave sintering, an emerging technology has been successfully applied to the sintering of different materials such as: complexshaped alumina with short processing time [14], finegrained $\mathrm{Al}_{2} \mathrm{O}_{3} / \mathrm{SiC}$ composite ceramic tool materials [15], yttrium-stabilized zirconia polycrystalline (Y-TZP) ceramics [16], zirconia nanocomposite powders doped with cerium and toughened with alumina (10Ce$\mathrm{TZP} / \mathrm{Al}_{2} \mathrm{O}_{3}$ ) [17], porous silicon nitride materials with controllable dielectric constant and pore structure [18], $\mathrm{Si}_{3} \mathrm{~N}_{4}$ ceramics with excellent mechanical properties and microstructure [19], the porous Ti-Cu alloys [20], PM stainless steel 316L [21], PM copper steel [22], aluminophosphate glass [23], metal doped borosilicate glass with controlled isolated porosity [24], metal-diamond composite material with excellent mechanical properties [25], the boronised Ti6Al4V/hydroxyapatite (HA) composites [26], titanium carbide in presence of different amount of $\mathrm{Ni}$ [27], etc. 
In this study, conventional (electrical) and nonconventional (hybrid microwave) sintered alumina ceramics were prepared and obtained properties were analysed and compared.

\section{MATERIALS AND METHODS}

A commercial, high purity $\mathrm{Al}_{2} \mathrm{O}_{3}$ powder (Alteo, France) was used in this research as raw material. According to the manufacturer's specification, the asreceived powder has an average particle size of $0.40 \mu \mathrm{m}$ and a surface area of $8.0 \mathrm{~m}^{2} / \mathrm{g}$. The chemical composition of raw alumina powder, according to manufacturer's declaration is shown in Tab. 1. According to the results of chemical composition analysis, raw $\mathrm{Al}_{2} \mathrm{O}_{3}$ powder has a high purity of 99.83 wt. \%. The presence of $\mathrm{MgO}$, as a sintering aid and the following impurities: $\mathrm{CaO}, \mathrm{Fe}_{2} \mathrm{O}_{3}$, $\mathrm{Na}_{2} \mathrm{O}$ and $\mathrm{SiO}_{2}$ were also confirmed.

Table 1 Chemical composition of raw alumina $\left(\mathrm{Al}_{2} \mathrm{O}_{3}\right)$ powder

\begin{tabular}{|c|c|c|c|c|c|c|}
\hline \multirow{2}{*}{ Sample } & \multicolumn{7}{|c|}{ wt. \% } \\
\cline { 2 - 7 } & $\mathrm{CaO}$ & $\mathrm{Fe}_{2} \mathrm{O}_{3}$ & $\mathrm{MgO}$ & $\mathrm{Na}_{2} \mathrm{O}$ & $\mathrm{SiO}_{2}$ & $\mathrm{Al}_{2} \mathrm{O}_{3}$ \\
\hline $\begin{array}{c}\mathrm{Al}_{2} \mathrm{O}_{3} \\
\text { powder }\end{array}$ & 0.0200 & 0.0180 & 0.0450 & 0.0500 & 0.0325 & balance \\
\hline
\end{tabular}

The preparation of alumina granules by spray drying, compaction of green bodies by cold isostatic pressing, as well as green machining of green compact bodies, were performed in Applied Ceramics, Inc., Sisak, Croatia. Morphology of powder and granules were examined by scanning electron microscope (SEM) (Tescan Vega TS5136LS, Czech Republic).

The alumina spray-dried granules were sieved into nine size fractions ranging: $<50 \mu \mathrm{m}$, from 50 to $100 \mu \mathrm{m}$, from 100 to $150 \mu \mathrm{m}$, from 150 to $200 \mu \mathrm{m}$, from 200 to 300 $\mu \mathrm{m}$, from 300 to $315 \mu \mathrm{m}$, and from 315 to $355 \mu \mathrm{m}$, from 355 to $500 \mu \mathrm{m},>500 \mu \mathrm{m}$, to determinate the granule size distribution (according to the ASTM E11-20) of the resulting spray-dried granules.

Apparent (bulk) density of granules was $\left(\rho, \mathrm{g} / \mathrm{cm}^{3}\right)$ estimated from their volumes (measured by dimensions) and masses (weighing). Apparent (bulk) density of granules was $123.2 \mathrm{~g} / 100 \mathrm{~mL}$. This volume includes pores within particles and voids between particles [28].

Powder X-ray diffraction (PXRD) analysis was used to determine phase compositions of the $\mathrm{Al}_{2} \mathrm{O}_{3}$ raw powder and granules. The device used was Shimadzu XRD6000 (Shimadzu Corporation, Kyoto, Japan) X-ray diffractometer with $\mathrm{CuK} \alpha$ radiation. The fixed step scans were collected in the range $20^{\circ}-60^{\circ} 2 \theta$ with steps of $0.02^{\circ}$ and counting time $0.6 \mathrm{~s}$ under accelerating voltage of $40 \mathrm{kV}$ and current of $30 \mathrm{~mA}$.

The simultaneous DTA/TGA device STA409 (Netzsch, Selb, Germany) was used for differential thermal analysis (DTA) and thermogravimetric analysis (TGA) of raw $\mathrm{Al}_{2} \mathrm{O}_{3}$ powder and spray-dried (SD) alumina granules. A platinum crucible was filled with approximately $5 \mathrm{mg}$ of material and heated up to $1100{ }^{\circ} \mathrm{C}$ at a heating rate of 10 ${ }^{\circ} \mathrm{C} / \mathrm{min}$ in the synthetic air flow of $30 \mathrm{~cm}^{3} / \mathrm{min}$, with corundum powder used as a reference.

Cold isostatic pressing (CIP) was used for forming green compact bodies in cylindrical pellets with a diameter of $10 \mathrm{~mm}$ and $20 \mathrm{~mm}$ height and randomly divided into two main sintering groups, 27 samples each.
The first group of cylindrical pellets (conventionally sintered $\mathrm{A}_{2} \mathrm{O}_{3}$ samples - group $\mathrm{CS}$ ) was sintered using an electric kiln (Nabertherm P310, Germany) at $1600{ }^{\circ} \mathrm{C}$ for $6 \mathrm{~h}$. The second group of cylindrical pellets (nonconventionally sintered $\mathrm{A}_{2} \mathrm{O}_{3}$ samples - group NCS) was sintered using a hybrid microwave kiln (Over industrijska elektronika d.o.o., Croatia) at $1600{ }^{\circ} \mathrm{C}$ for $1 \mathrm{~h}$. The hybrid microwave-electric kiln was used at low-frequency 2.45 $\mathrm{GHz}$ and $1.5 \mathrm{~kW}$ microwave magnetron. A silicon carbide susceptor was used to aid the heating of the sample in the microwave cavity.

For all sintered samples, density and shrinkage (radial and axial) were determined. The green densities $\left(\rho, \mathrm{g} / \mathrm{cm}^{3}\right)$ were determined by measuring the mass of green bodies $(m, \mathrm{~g})$ and volume $\left(V, \mathrm{~cm}^{3}\right)$ of green bodies by using the following equation:

$\rho=\frac{m}{V}$

Mass of the green bodies was measured by analytical balance Ohaus AP250D. Sintered density was determined by Archimedes' method. Dimensions (diameter and height) of sintered cylindrical pellets were measured in order to calculate the radial and axial shrinkage of ceramics due to the sintering. The diameter $(d, \mathrm{~mm})$ and height $(h, \mathrm{~mm})$ was measured by a Vernier calliper (Digimatic, Mitutoyo). The radial shrinkage $(R S)$ was calculated by the following equation:

$$
R S=\frac{d_{\mathrm{g}}}{d_{\mathrm{s}}-d_{\mathrm{g}}} \cdot 100, \%
$$

where $d_{\mathrm{g}}$ is the average diameter of the alumina green body, $d_{\mathrm{s}}$ is the average diameter of the sintered alumina sample.

The axial shrinkage $(A S)$ was calculated as the reduction of the green body height by the following equation:

$$
A S=\frac{h_{\mathrm{g}}}{h_{\mathrm{s}}-h_{\mathrm{g}}} \cdot 100, \%
$$

where $h_{\mathrm{g}}$ is the average height of the green alumina body, $h_{\mathrm{s}}$ is the average height of the sintered alumina sample.

Sintered density was evaluated using the Archimedes method (Mettler Toledo GmbH, Switzerland, density kit MS-DNY-43) according to the ASTM C373-88.

Relative densities of sintered samples were calculated by the following equation:

$\rho_{\text {relative }}=\frac{\rho_{\text {Archimeds }}}{\rho_{\text {theoretical }}} \cdot 100, \%$

Theoretical density of $\alpha$-alumina is $3.987 \mathrm{~g} / \mathrm{cm}^{3}$, [29].

Morphology of fracture surface of samples sintered by both techniques was analysed by scanning electron microscope (SEM) (Tescan Vega TS5136LS, Czech Republic). 


\section{RESULTS AND DISCUSSION}

Morphology of the ready to press granules of different sizes can be seen in Fig. 2. Most of the particles are spherically shaped, while some particles with defects are also present.
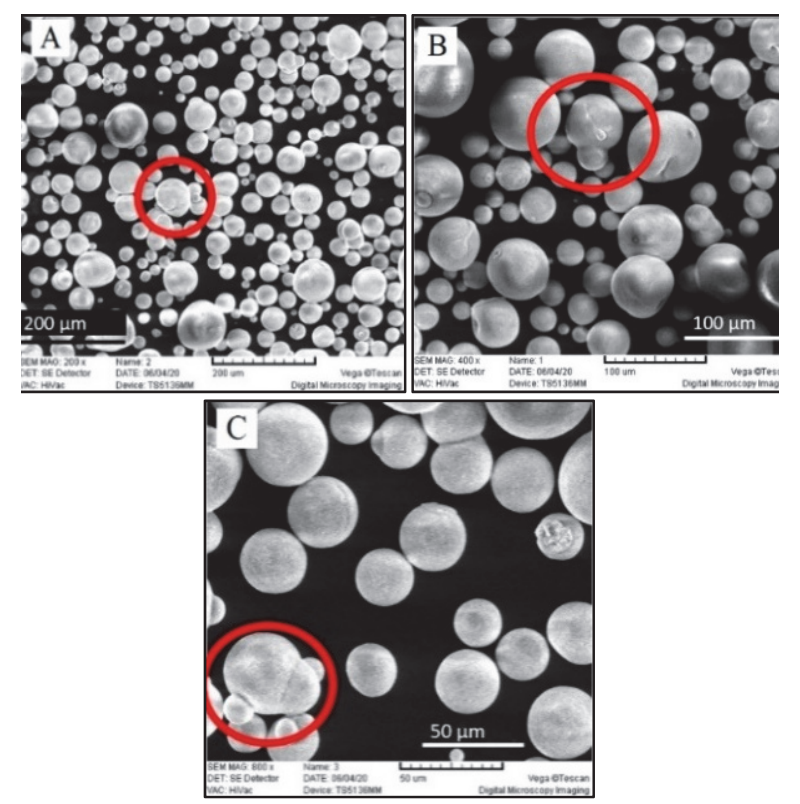

Figure 2 Morphology of $\mathrm{Al}_{2} \mathrm{O}_{3}$ granules at magnification of (a) 200x; (b) $400 \times$ and (c) $800 x$

Particle size distribution, that follows a normal distribution (Fig. 3), shows that $96 \%$ of particles are in the range from 50 up to $300 \mu \mathrm{m}$. Particle's shape and size distribution are important properties of the powder because of ensuring the proper filling the mould in the process of green body production [28].

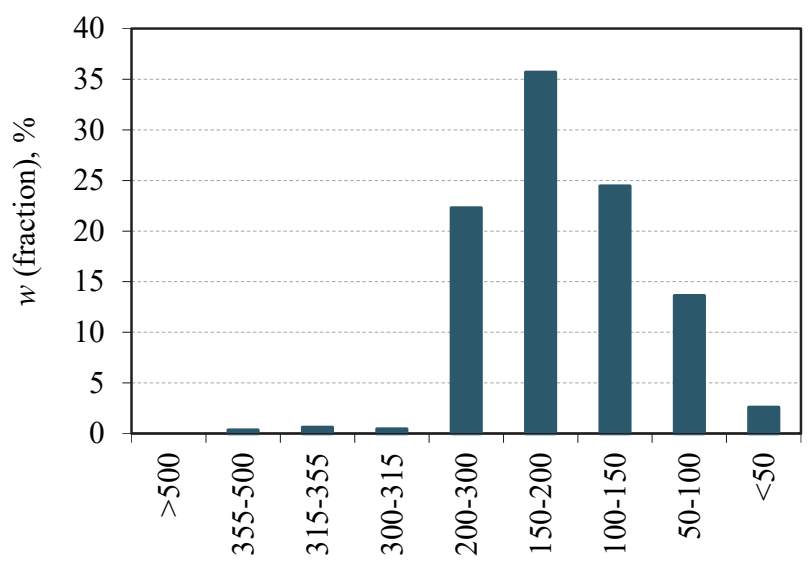

diameter ranges, $\mathrm{mm}$

Figure 3 Particle size distribution of the spray-dried alumina granules

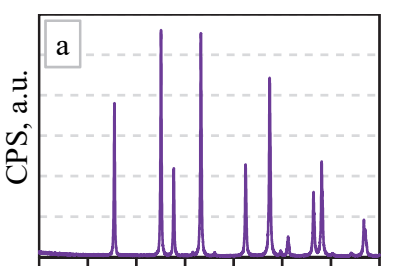

$\begin{array}{llllllll}10 & 20 & 30 & 40 & 50 & 60 & 70 & 80\end{array}$ $2 \Theta /{ }^{\circ} \mathrm{CuK} \alpha$

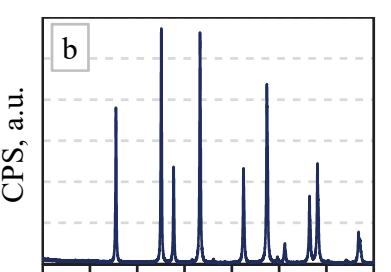

$\begin{array}{llllllll}10 & 20 & 30 & 40 & 50 & 60 & 70 & 80\end{array}$ $2 \Theta /{ }^{\circ} \mathrm{CuK} \alpha$
Figure 4 XRD patterns of (a) raw $\mathrm{Al}_{2} \mathrm{O}_{3}$ powder and (b) $\mathrm{Al}_{2} \mathrm{O}_{3}$ granules
XRD diffractograms (Fig. 4) of the $\mathrm{Al}_{2} \mathrm{O}_{3}$ raw powder and granules show the presence of characteristic peaks of only one phase that is $\alpha-\mathrm{Al}_{2} \mathrm{O}_{3}$.

DTA and TGA thermograms of raw $\mathrm{Al}_{2} \mathrm{O}_{3}$ powder and granules are shown in Fig. 5.

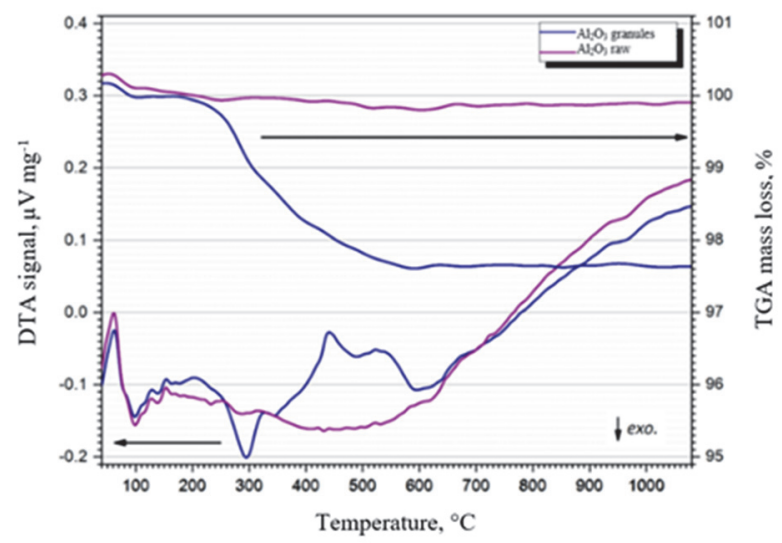

Figure 5 DTA and TGA thermogram of $\mathrm{Al}_{2} \mathrm{O}_{3}$ raw powder and granules

For alumina powder TGA curve shows the mass loss in the range from room temperature up to $150{ }^{\circ} \mathrm{C}$ that presents evaporation of water absorbed in the raw powder. DTA equivalent at this temperature range shows endotherm peak. No further effects are visible for the raw powder up to $1100{ }^{\circ} \mathrm{C}$ and mass loss of about $0.2 \%$.

$\mathrm{Al}_{2} \mathrm{O}_{3}$ granules have almost identical effect of water evaporation up to $150{ }^{\circ} \mathrm{C}$. Multiple overlapped further effects are present in the range of $200-600^{\circ} \mathrm{C}$, as confirmed from significant mass loss is present in this temperature range. In the range $200-350{ }^{\circ} \mathrm{C}$, exotherm peak centred at about $300{ }^{\circ} \mathrm{C}$ presents burning of organic additives (binders, plasticizers etc.).

Further, at the range of $350-600{ }^{\circ} \mathrm{C}$ partly overlapped endotherm peaks indicate graduate release and burning of the rest of the organic additives that is followed by gradual mass loss. Over $600{ }^{\circ} \mathrm{C}$ until the end of the measurement $\left(1100{ }^{\circ} \mathrm{C}\right)$ no further thermal effects are present. Mass loss of the granules at the end of the measurement is about $2.5 \%$ in total.

The average and standard deviation of dimensions (diameter $(d)$ and height $(h)$ ), the mass of the green bodies and compacts sintered by conventional (ES - electrical kiln) and non-conventional (MWS - hybrid microwave kiln) sintering method as well as density of green bodies and sintered compacts are shown in Tab. 2.

Table 2 The dimensions, mass and density of green bodies and sintered compacts in ES - electrical kiln and MWS - hybrid microwave kiln (average value \pm experimental standard deviation)

\begin{tabular}{|c|c|c|c|}
\hline \multirow[b]{2}{*}{ Properties } & \multirow{2}{*}{$\begin{array}{c}\mathrm{Al}_{2} \mathrm{O}_{3} \\
\text { green body } \\
(\mathrm{GB})\end{array}$} & \multicolumn{2}{|c|}{ Sintered $\mathrm{Al}_{2} \mathrm{O}_{3}$} \\
\hline & & $\begin{array}{l}\text { Conventionally } \\
\text { sintered (ES) }\end{array}$ & $\begin{array}{l}\text { Non-conventionally } \\
\text { sintered (MWS) }\end{array}$ \\
\hline$h / \mathrm{mm}$ & $19.89 \pm 0.07$ & $16.50 \pm 0.06$ & $16.72 \pm 0.17$ \\
\hline$d / \mathrm{mm}$ & $9.95 \pm 0.05$ & $8.25 \pm 0.05$ & $8.38 \pm 0.09$ \\
\hline$m / g$ & $3.520 \pm 0.012$ & $3.489 \pm 0.015$ & $3.406 \pm 0.017$ \\
\hline$\rho / \mathrm{g} / \mathrm{cm}^{3}$ & $2.275 \pm 0.028$ & $3.864 \pm 0.018$ & $3.784 \pm 0.028$ \\
\hline
\end{tabular}

During the sintering process, all green cylindrical pellets were shrunk, both radially and axially (Fig. 6).

Linear sintering shrinkage (radially and axially) due to the sintering of compacts was about $16-17 \%$ (Figs. 6a, 6b). It was found that slightly higher linear shrinkage (radial 
and axial) was obtained for alumina samples sintered in an electric kiln (conventional method).

Green density, as well as sintered densities, are shown in Fig. 6c. It was found that slightly higher density was obtained for alumina samples sintered in an electric kiln $\left(3.864 \pm 0.018 \mathrm{~g} / \mathrm{cm}^{3}\right)$ than in hybrid microwave kiln $\left(3.784 \pm 0.028 \mathrm{~g} / \mathrm{cm}^{3}\right)$. However, higher dissipation of the results can be observed for dimensions and density values of the non-conventional sintered samples (Fig. 6).
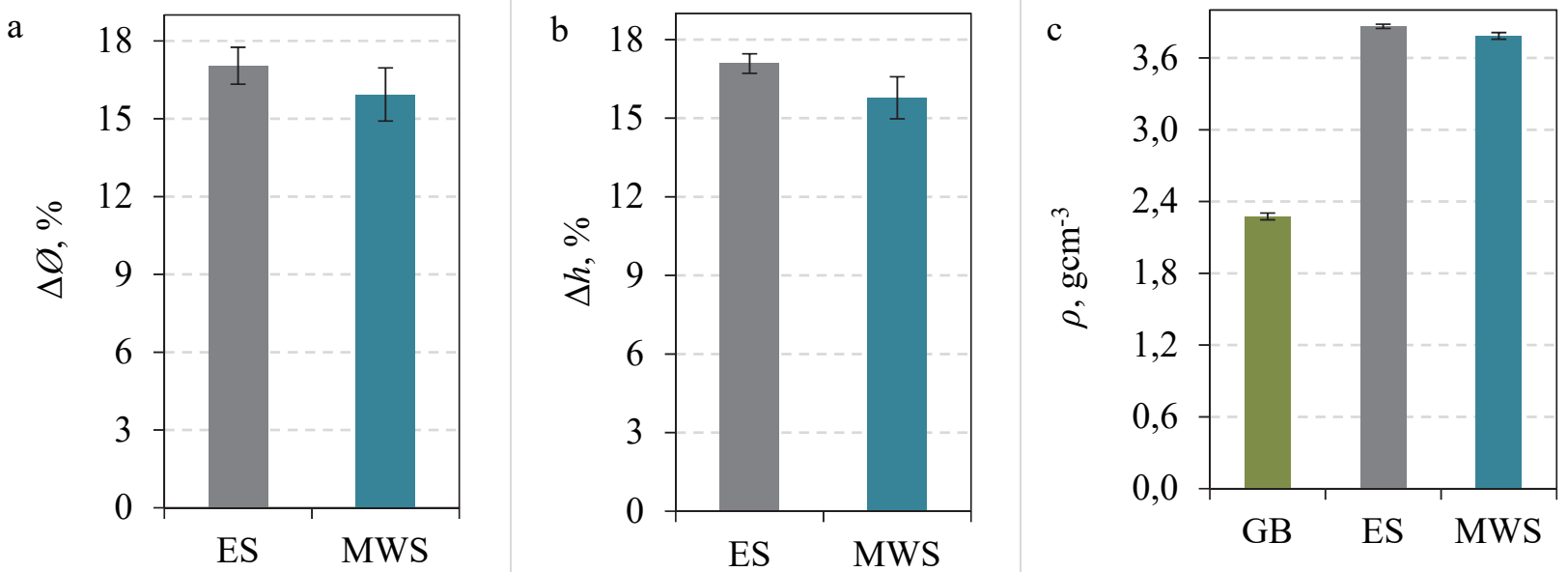

Figure 6 Alumina samples sintered by conventional (ES - electrical kiln) and non-conventional (MWS - hybrid microwave kiln) techniques: (a) radial shrinkage; (b) axial shrinkage; (c) the green and sintered density (average value \pm experimental standard deviation)

Morphology of fracture surface of $\mathrm{Al}_{2} \mathrm{O}_{3}$ ceramics sintered by conventional (electrical) and non-conventional (hybrid microwave) sintering is shown in Fig. 7.

It was found that finer grain size was obtained for alumina samples sintered by hybrid microwave kiln (nonconventional sintering method). Thereby the processing took less time and it was more energy efficient.

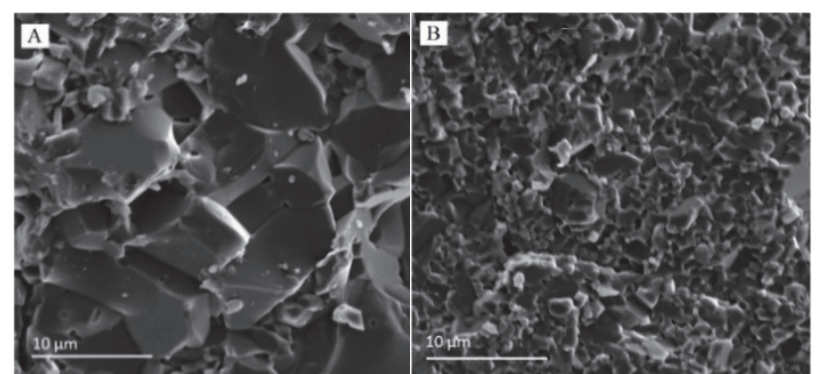

Figure $7 \mathrm{SEM}$ images of the fracture surface of $\mathrm{Al}_{2} \mathrm{O}_{3}$ ceramics sintered by (a) conventional (electrical kiln) and (b) non-conventional (hybrid microwave kiln) sintering

Relative density and porosity of the green bodies, as well as samples sintered by conventional and nonconventional method, are presented in Tab. 3 .

Samples sintered in electrical kiln obtained higher density and less porosity compared to the samples sintered in the hybrid-microwave kiln.

Further research should be conducted in the way of further development of hybrid microwave sintering method and reaching density of alumina samples as much as possible close to the theoretical density value.

Table 3 Relative density and porosity of conventionally (ES - electrical kiln) and non-conventionally (MWS - hybrid microwave kiln) sintered alumina samples (average value \pm experimental standard deviation)

\begin{tabular}{|c|c|c|}
\hline \multirow{2}{*}{ Properties } & \multicolumn{2}{|c|}{ Sintered $\mathrm{Al}_{2} \mathrm{O}_{3}$} \\
\cline { 2 - 3 } & $\begin{array}{c}\text { Conventionally } \\
\text { sintered (ES) }\end{array}$ & $\begin{array}{c}\text { Non-conventionally } \\
\text { sintered (MWS) }\end{array}$ \\
\hline Relative density / \% & $96.9 \pm 0.5$ & $94.9 \pm 0.7$ \\
\hline Porosity / \% & $3.1 \pm 0.5$ & $5.1 \pm 0.7$ \\
\hline
\end{tabular}

\section{CONCLUSIONS}

Comparison of the conventional (electrical kiln) and non-conventional sintering (hybrid microwave kiln) of high purity alumina ceramics was evaluated. Next conclusions can be pointed out:

- Cold isostatic pressing was used for compaction and shaping of high-purity alumina ceramics.

- Alumina samples sintered in electrical kiln have slightly higher linear shrinkage (radially and axially) and sintered density than alumina samples sintered in hybrid microwave kiln.

- Alumina samples sintered in electrical kiln have larger grain size, while alumina samples sintered in hybrid microwave kiln have finer grain size.

- Lower relative density and consequently higher presence of pores in the structure was obtained for alumina samples sintered in hybrid microwave kiln.

According to those observations, it can be concluded that alumina samples sintered by faster and more energy efficient hybrid microwave kiln have finer grain size than conventionally (electrical kiln) sintered alumina samples.

\section{Acknowledgements}

This work has been fully supported by Croatian Science Foundation under the project IP-2016-06-6000: "Monolithic and composite advanced ceramics for wear and corrosion protection" (WECOR).

\section{REFERENCES}

[1] Ćurković, L., Majić Renjo, M., \& Ciglar, D. (2015). Effects of cold isostatic pressing and granule size distribution on the densification of alumina ceramics. Materials Testing, 57(6), 1-4. https://doi.org/10.3139/120.110739

[2] Greenwood, N. N. \& Earnshaw, A. (2012). Chemistry of the Elements. Butterworth-Heinemann.

[3] Žmak, I., Ćorić, D., Mandić, V., \& Ćurković, L. (2020). Hardness and Indentation Fracture Toughness of Slip Cast 
Alumina and Alumina-Zirconia Ceramics. Materials, 13, 117. https://doi.org/10.3390/ma13010122

[4] Figiel, P., Rozmus, M., \& Smuk, B. (2011). Properties of alumina ceramics obtained by conventional and nonconventional methods for sintering ceramics. Journal of Achievements in Materials and Manufacturing Engineering, 48(1), 29-34.

[5] Gutiérrez, A. V., Cuevas, J. L., Ángeles, A. G., \& Pilalua, N. (2019). Addition of ceramics materials to improve the corrosion resistance of alumina refractories. SN Applied Sciences, 1(7), 1-7. https://doi.org/10.1007/s42452-019-0789-5

[6] Vukšić, M., Žmak, I., Ćurković, L., \& Ćorić, D. (2019). Effect of Additives on Stability of Alumina - Waste Alumina Suspension for Slip Casting: Optimization Using BoxBehnken Design. Materials, 12, 1-16. https://doi.org/10.3390/ma12111738

[7] Sever, I., Žmak, I., Ćurković, L., \& Švagelj, Z. (2018). Stabilization of highly concentrated alumina suspensions with different dispersants. Transactions of FAMENA, 3(72), 61-70. https://doi.org/10.21278/TOF.42304

[8] Medvedovski, E. (2013). Influence of corrosion and mechanical loads on advanced ceramic components. Ceramics International, 39(3), 2723-2741 https://doi.org/10.1016/j.ceramint.2012.09.040

[9] Lóh, N. J., Simão, L., Jiusti, J., De Noni Jr., A., \& Montedo, O. R. K. (2017). Effect of temperature and holding time on the densification of alumina obtained by two-step sintering. Ceramics International, 43(11), 8269-8275. https://doi.org/10.1016/j.ceramint.2017.03.159

[10] Tian, Q., Dai, J., Xu, L., \& Wang, X. (2016). Advance of Sintering Methods of High Purity Alumina Ceramics. Key Engineering Materials, 703, 76-80. https://doi.org/10.4028/www.scientific.net/KEM.703.76

[11] Agrawal, D. (2010). Sintering of Advanced Materials. Woodhead Publishing. https://doi.org/10.1533/9781845699949.2.222

[12] Zuo, F., Badev, A., Saunier, S., Goeuriot, D., Heuguet, R., \& Marinel, S. (2014). Microwave versus conventional sintering: Estimate of the apparent activation energy for densification of $\alpha$-alumina and zinc oxide. Journal of the European Ceramic Society, 34, 3103-3110. https://doi.org/10.1016/j.jeurceramsoc.2014.04.006

[13] Rodrigues, R., Marcia, P., Herta, R., \& Aliaga, G. (2010). Microwave Fast Sintering of Submicrometer Alumina. Materials Research, 13(3), 345-350. https://doi.org/10.1590/S1516-14392010000300011

[14] Curto, H., Thuault, A., Jean, F., Violier, M., Dupont, V., Hornez, J. C., \& Leriche, A. (2020). Coupling additive manufacturing and microwave sintering: a fast processing route of alumina ceramics. Journal of the European Ceramic Society, 40(7), 2548-2554. https://doi.org/10.1016/j.jeurceramsoc.2019.11.009

[15] Hong, D., Yin, Z., Yan, S., \& Xu, W. (2019). Fine grained $\mathrm{Al}_{2} \mathrm{O}_{3} / \mathrm{SiC}$ composite ceramic tool material prepared by twostep microwave sintering. Ceramics International, 45(9), 11826-11832. https://doi.org/10.1016/j.ceramint.2019.03.061

[16] Presenda, Á., Salvador, M. D., Peñaranda-Foix, F. L., Moreno, R., \& Borell, A. (2015). Effect of microwave sintering on microstructure and mechanical properties in $\mathrm{Y}$ TZP materials used for dental applications. Ceramics International, 41(5), 7125-7132. https://doi.org/10.1016/j.ceramint.2015.02.025

[17] Gil-Flores, L., Salvador, M. D., Penaranda-Foix, F. L., Fernández, A., Suarez, M., Rosa, R., Borrell, A. et al. (2019). Microstructure and mechanical properties of $5.8 \mathrm{GHz}$ microwave-sintered $\mathrm{ZrO}_{2} / \mathrm{Al}_{2} \mathrm{O}_{3}$ ceramics. Ceramics International journal, 45, 18059-18064. https://doi.org/10.1016/j.ceramint.2019.06.026

[18] Chun-fang, X. \& Bing, H. A. N. (2019). Preparation of porous silicon nitride ceramics by microwave sintering and its performance. Journal of Materials Research and Technology, 8(6), 5984-5995. https://doi.org/10.1016/j.jmrt.2019.09.073

[19] Xu, W., Yin, Z., Yuan, J., Wang, Z., \& Fang, Y. (2017). Effects of sintering additives on mechanical properties and microstructure of Si3N4 ceramics by microwave sintering. Materials Science \& Engineering A, 684, 127-134. https://doi.org/10.1016/j.msea.2016.12.031

[20] Tao, S. C., Xu, J. L., Yuan, L., Luo, J. M., \& Zheng, Y. F. (2020). Microstructure, mechanical properties and antibacterial properties of the microwave sintered porous Ti3Cu alloys. Journal of Alloys and Compounds, 812, 152142. https://doi.org/10.1016/j.jallcom.2019.152142

[21] Nagaraju, K. V. V., Kumaran, S., \& Srinivasa Rao, T. (2020). Microwave sintering of $316 \mathrm{~L}$ stainless steel : Influence of sintering temperature and time. Materials Today: Proceedings, 27(3), 2066-2071. https://doi.org/10.1016/j.matpr.2019.09.062

[22] Anklekar, R. M., Agrawal, D. K., \& Roy, R. (2001). Microwave sintering and mechanical properties of PM copper steel. Powder Metallurgy, 44(4), 355-362. https://doi.org/10.1179/pom.2001.44.4.355

[23] Mandal, A. K., Biswas, K., \& Annapurna, K. (2013). Preparation of alumino-phosphate glass by microwave radiation. Materials Research, 28(14), 1955-1961. https://doi.org/10.1557/jmr.2013.168

[24] Boccaccini, A. R., Veronesi, P., \& Leonelli, C. (2001). Microwave processing of glass matrix composites containing controlled isolated porosity. Journal of the European Ceramic Society, 21, 1073-1080. https://doi.org/10.1016/S0955-2219(00)00319-8

[25] Hou, M., Gao, J., Yang, L., Ullah, E., Hu, T., Guo, S., Hu, L., Li, Y. (2020). The role of pre-alloyed powder combined with pressure-less microwave sintering on performance of superhard materials. Journal of Alloys and Compounds, 831, 154744. https://doi.org/10.1016/j.jallcom.2020.154744

[26] Peng, Q., Tang, Z., Wang, Y., \& Peng, Z. (2019). Mechanical performance and in-vitro biological behaviors of boronized Ti6Al4V/HA composites synthesized by microwave sintering. Ceramics International, 45(18), 24684-24690. https://doi.org/10.1016/j.ceramint.2019.08.207

[27] Vasudevan, N., Ahamed, N. N. N., Pavithra, B., Aravindhan, A. \& Shanmugavel, B. P. (2020). Effect of Ni addition on the Densification of TiC: A Comparative Study of Conventional and Microwave Sintering. International Journal of Refractory Metals and Hard Materials, 87, 105165. https://doi.org/10.1016/j.jirmhm.2019.105165

[28] Stunda-Zujeva, A., Irbe, Z., \& Berzina-Cimdina, L. (2017). Controlling the morphology of ceramic and composite powders obtained via spray drying - A review. Ceramics International, 43(15), 11543-11551. https://doi.org/10.1016/j.ceramint.2017.05.023

[29] Cho, K. S., Min, J. H., Lee, H. K., \& Kim, H. D. (2020). Reducing the density deviation in alumina by pressurevacuum hybrid slip casting by employing powders with different particle sizes. Journal of Asian Ceramic Societies, 8(2), 407-415. https://doi.org/10.1080/21870764.2020.1749372

\section{Contact information:}

Ivana ROPUŠ, mag. ing. mech., PhD candidate

(Corresponding author)

Energo attest zaštita d.o.o.

Potočnjakova 4, Zagreb, Croatia

E-mail: ivanaropus@gmail.com

Lidija ĆURKOVIĆ, PhD, Full Professor

Faculty of Mechanical Engineering and Naval Architecture, University of Zagreb, Ivana Lučića 5, Zagreb, Croatia

E-mail: lidija.curkovic@fsb.hr 
Vilko MANDIĆ, PhD, Associate Professor

Faculty of Chemical Engineering and Technology,

University of Zagreb,

Marulićev trg 20, 10000 Zagreb, Croatia

E-mail: vmandic@fkit.hr

Mihone KEROLLI MUSTAFA, PhD, College Director

International Business College Mitrovica

Str. Bislim Bajgorann, 40000 Mitrovica, Kosovo

E-mail: m.kerolli@ibcmitrovica.eu

Ivana GABELICA, mag. ing. PhD candidate

Faculty of Mechanical Engineering and Naval Architecture, University of Zagreb

Ivana Lučića 5, Zagreb, Croatia

E-mail: ivana.gabelica@fsb.hr 